\title{
Fractionation of sulfur isotopes in the preparation of sulfur dioxide. An improved technique for the precision analysis of stable sulfur isotopes
}

\author{
Hitoshi Sakai and Masahiro Yamamoto \\ Institute for Thermal Spring Research, Okayama University, \\ Misasa, Tottori-Pref., Japan
}

(Received June 4, 1966)

\begin{abstract}
It is definitely shown that the main cause of error encountered in the precision isotope analysis of sulfur is in the isotope exchange reaction between $\mathrm{SO}_{2}$ and $\mathrm{SO}_{3}$ during the combustion process of $\mathrm{SO}_{2}$ preparation. The isotope fractionation factor between the two oxides is estimated to be 1.0035 at $1200^{\circ} \mathrm{C}$. From this value, it is predicted that $3 \%$ fluctuation in the yield of $\mathrm{SO}_{2}$ would introduce uncertainty of $0.1 \%$ in the results of the ratio measurement.

An improved combustion technique to maintain a constant yield of $\mathrm{SO}_{2}$ is described where pure oxygen is replaced by a nitroden-oxygen mixture $(15: 1, \mathrm{v} / \mathrm{v})$.
\end{abstract}

\section{INTRODUCTION}

Isotope fractionation of sulfur during chemical and geochemical processes has been studied by a number of researchers in these fields. The mass spectrometer technique employed for this purpose is accurate enough to reproduce as small a difference of isotope ratio as $0.1 \%$ in $\delta S$ scale defined below:

$$
\delta S(\%)=\left[\frac{\left({ }^{34} \mathrm{~S} /{ }^{32} \mathrm{~S}\right)_{\mathrm{x}}}{\left({ }^{34} \mathrm{~S} /{ }^{32} \mathrm{~S}\right)_{\mathrm{st}}}-1\right] \times 1000,
$$

where $x$ and st respectively represent a sample to be measured and a working standard to which the sample is compared.

A standard procedure for conversion of sulfur compounds into sulfur dioxide for mass spectrometric analysis consists of two major steps. In the first place, all compounds are converted to silver sulfide, $\mathrm{Ag}_{2} \mathrm{~S}$, and secondly, it is burned into sulfur dioxide in a stream of purified oxygen at a sufficiently high temperature. However, it has long been known that the second process introduces an extrasource of error to the isotope ratio measurement and the overall reproducibility of the results is decreased more than twice as expected from purely instrumental error. The reason for this is also known to be due to the formation of sulfur trioxide and/or sulfate in the combustion process. A small amount of these sulfur oxides favors the heavy isotopes of sulfur through isotope exchange equilibrium 
with sulfur dioxide, making the isotope ratio of the latter lower than the real value.

THODE et al. (1961) theoretically calculated that the isotope fractionation factor between sulfur trioxide and dioxide is 1.003 at $900^{\circ} \mathrm{C}$ and 1.001 at $1300^{\circ} \mathrm{C},{ }^{34} \mathrm{~S}$ being favored in the former. They concluded from the yield of $\mathrm{SO}_{2}$ and the fractionation factor that the error due to the process is negligible if the combustion temperature is above $1350^{\circ} \mathrm{C}$. RAFTER (1957) studied the combustion characteristics of silverand lead-sulfide. According to his results, an appreciable amount of silver sulfate is formed below $700^{\circ} \mathrm{C}$, which evolves $\mathrm{SO}_{2}$ slowly above $900^{\circ} \mathrm{C}$. He experimentally found that sulfate sulfur formed in one case was $6.8 \%$ heavier than sulfur dioxide collected at the temperature in the same run.

During the course of study to find out a better combustion procedure for routine isotope analysis of sulfur, we have made a rather quantitative observation on the isotope fractionation, the temperature dependence and the effect on the final results of ratio measurement.

In the present paper, discussion will be made on the results of these study and an improved technique for the combustion of $\mathrm{Ag}_{2} \mathrm{~S}$ in a stream of a $\mathrm{N}_{2}-\mathrm{O}_{2}$ mixture will be described.

\section{ExPERIMENTAL}

Preparation of sulfur dioxide from silver sulfide A schematic diagram of pre-, paration and purification system is shown in Fig. 1. About $120 \mathrm{mg}$ of silver sulfide weighed in an alumina boat, is quickly inserted into the center of the transparent quartz tube, which has been kept at a desired temperature by a regulated silicon carbide furnace. Oxygen or nitrogen-oxygen mixture is purified by passing it through Ascarite and then magnesium perchlorate. The flow rate is kept at about $60 \mathrm{ml} / \mathrm{min}$. throughout the experiment.

In order to prevent the condensation of oxygen in the traps 1 and 2 which are

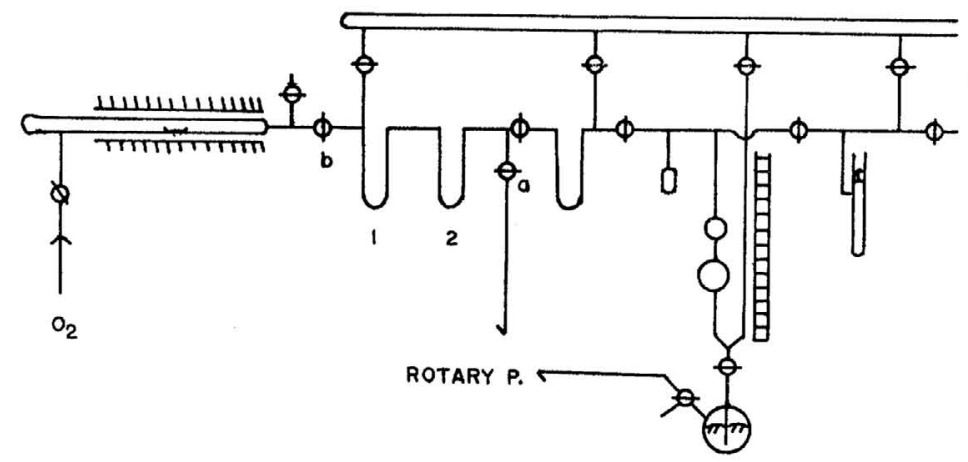

Fig. 1. Schematic diagram of the system for preparation and purification of sulfur dioxide. 
cooled by liquid nitrogen, a pressure around a few $\mathrm{mm} \mathrm{Hg}$ has to be maintained in the traps. This is achieved by pumping the carrier gas through the stopcock $a$ and a constriction between the stopcock $b$ and the trap 1. The complete collection of sulfur dioxide into the traps is obtained within $15 \mathrm{~min}$.

The amount of sulfur dioxide obtained in each run is usually determined by the constant volume manometer shown in Fig. 1. Carbon dioxide is removed before the volume measurements by the procedure described below.

Removal of carbon dioxide Carbon dioxide up to a few percents is always found in sulfur dioxide. By some reasons not well understood, its presence causes a considerable error in the ratio measurements. The effect is not constant from time to time, but, in one occasion, we found that $5 \%$ carbon dioxide contamination lowered $\delta S$ value by $1.5 \%$. Carbon dioxide is pumped away from sulfur dioxide at the melting point of $n$-pentane $\left(-131^{\circ} \mathrm{C}\right)\left(\mathrm{O}_{\mathrm{ANA}}, 1966\right)$. At this temperature, the vapor pressure of sulfur dioxide is less than $10^{-2} \mathrm{~mm} \mathrm{Hg}$, while that of carbon dioxide is as high as $2 \mathrm{~mm} \mathrm{Hg}$. Thus, only $1 \mathrm{~min}$. pumping is enough to remove more than $95 \%$ of carbon dioxide present without loss of sulfur dioxide. In order to ensure that no isotope fractionation is introduced by this process, two kinds of sulfur dioxide was analyzed for the isotope ratio before and after the $n$-pentane procedure. The results are presented in Table 1 .

Table 1. Isotope effect in the removal of carbon dioxide

\begin{tabular}{|c|c|c|}
\hline Sample No. & 1 & 2 \\
\hline$\delta S-a^{*}$ & $+1.12 \pm 0.08$ & $+10.13 \pm 0.08$ \\
\hline$\delta S-b^{* *}$ & $+1.16 \pm 0.08$ & $+10.29 \pm 0.12$ \\
\hline
\end{tabular}

Mass spectrometer system The mass spectrometer system used for the present work is essentially the same as that described by WAnLEss and THODE (1950). The details of our system was described previously (SAKAI, 1966). Precision of the isotope analysis is believed to be within $\pm 0.1 \%$ as long as purely instrumental errors are concerned. A stocked sample of sulfur dioxide was measured against a same working standard several times over a period of three weeks. The $\delta \mathrm{S}$ values found were $+10.2_{2},+10.2_{3},+10.2_{7},+10.1_{4}$ and $+10.2_{6} \%$, respectively.

\section{Theoretical Consideration}

The yield of sulfur dioxide at a high temperature is apparently controlled by the following equilibrium reaction:

$$
\mathrm{SO}_{2}+1 / 2 \mathrm{O}_{2} \rightleftharpoons \mathrm{SO}_{3}
$$


The equilibrium constant, $K_{p}$, expressed in partial pressures of the components under one atmospheric pressure, is related to the yield of sulfur dioxide, $Y$, as follows:

$$
Y=1 /\left(1+K_{p} P_{\sigma_{2}}^{1 / 2}\right)
$$

where $\mathrm{Po}_{2}$ is the partial pressure of oxygen in the combustion tube. $K_{p}$ can be estimated from the Gibbs free energy difference, $\Delta F_{f}$ between sulfur trioxide and dioxide. In this paper, the following expression is used for the evaluation of the free energy data (PITzer and Brewer, 1961).

$$
\Delta F_{f}^{0}=-22,700+21.29 \mathrm{~T} \mathrm{cal} / \mathrm{mol}
$$

Estimation of $P_{\mathrm{O}_{2}}$ is difficult, however, as it depends on a number of factors such as flow rate of oxygen, combustion rate of the sulfide, and mixing of oxygen and sulfur dioxide. In the present work, silver sulfide equivalent to ca. $10 \mathrm{ml}$ STP of sulfur dioxide is burned in a quartz tube of ca. $4 \mathrm{~cm}^{2}$ cross section. When pure oxygen is used, the combustion takes place most violently, the sulfide being bursted in flame, and, therefore, the oxygen concentration near the sulfide would be locally decreased. It does not seem plausible to assume uniform mixing of sulfur dioxide and oxygen before they leave the high temperature portion of the furnace.

For these reasons, in Table 2 are shown the yield of sulfur dioxide calculated for various partial pressures of oxygen at temperatures from 800 to $1200^{\circ} \mathrm{C}$.

Table 2. Yield of sulfur dioxide at various temperatures

\begin{tabular}{cccccc}
\hline \hline$T^{\circ} \mathrm{C} \rightarrow$ & \multicolumn{5}{c}{ Yield of $\mathrm{SO}_{2} \%$} \\
$P_{\mathrm{n}_{2} \downarrow}$ & 800 & 900 & 1000 & 1100 & 1200 \\
\hline 1 & 51.2 & 72.2 & 85.3 & 91.5 & 95.1 \\
$1 / 2$ & 59.7 & 78.7 & 88.0 & 93.9 & 96.5 \\
$1 / 5$ & 70.2 & 85.2 & 92.1 & 96.1 & 97.6 \\
$1 / 10$ & 76.8 & 89.2 & 94.3 & 97.2 & 98.4 \\
$1 / 20$ & 82.4 & 92.1 & 95.9 & 97.9 & 98.8 \\
\hline
\end{tabular}

On the other hand, the isotope ratio of sulfur dioxide is determined by the following isotope exchange reaction with sulfur trioxide:

$$
{ }^{32} \mathrm{SO}_{3}+{ }^{34} \mathrm{SO}_{2} \rightleftharpoons{ }^{34} \mathrm{SO}_{3}+{ }^{32} \mathrm{SO}_{2}
$$

Recalling the definition of $\delta S$ and considering isotopic material balance, the yield of sulfur dioxide and its isotope ratio are related in the following equation:

$$
1000+\delta S^{0}=\left[Y+(1-Y) K_{i}\right]\left(1000+\delta S_{m}\right),
$$

where $\delta S^{0}$ and $\delta S_{m}$ are the true isotope ratio of silver sulfide and that of sulfur dioxide collected, respectively, and $K_{i}$ denotes the equilibrium constant of the reaction 3). Assuming that $\alpha=K_{i}-1$ is small, the equation can be reduced into a 
simpler form as below:

$$
\delta S_{m}=\delta S^{0}-\alpha(1-Y) 10^{3}
$$

In the equation 4) $\alpha$ has an order of magnitude of $n \times 10^{-3}$ above $1000^{\circ} \mathrm{C}$ as expected from the theoretical calculation (Thode et al., 1961). Thus 1\% variation in the yield of sulfur dioxide would cause $0.0 n \%$ variation in the isotope ratio measurement.

\section{Results And Discussion}

Results by pure oxygen technique Yields of sulfur dioxide and its isotope ratios were measured on more than 50 runs at temperatures from 800 to $1200^{\circ} \mathrm{C}$ using the pure oxygen combustion technique and a same silver sulfide sample. Two important observations were made as follows:

(1) The yields obtained with a new quartz tube are in good agreement with those estimated in Table 2. At $1200^{\circ} \mathrm{C}$, for instance, 95 to $96 \%$ of sulfur is usually collected as sulfur dioxide.

(2) However, as the quartz tube is devitrified rather rapidly during several runs, the yield is found to show continuous decrease. In one of the tubes run at $1200^{\wedge} \mathrm{C}$, the yield never exceeded $60 \%$ after about 15 samples were treated.

The second point is rather surprising to the present authors. Qualitatively, it may be explained if rough surface of the devitrified quartz tends to selectively trap sulfur trioxide or if sulfur trioxide initially formed in more than equilibrium amount is stabilized on the surface.

This unexpected fact, however, allows us to examine the equation 4), because a number of sulfur dioxide samples are obtained of which yield varies over a suffici-

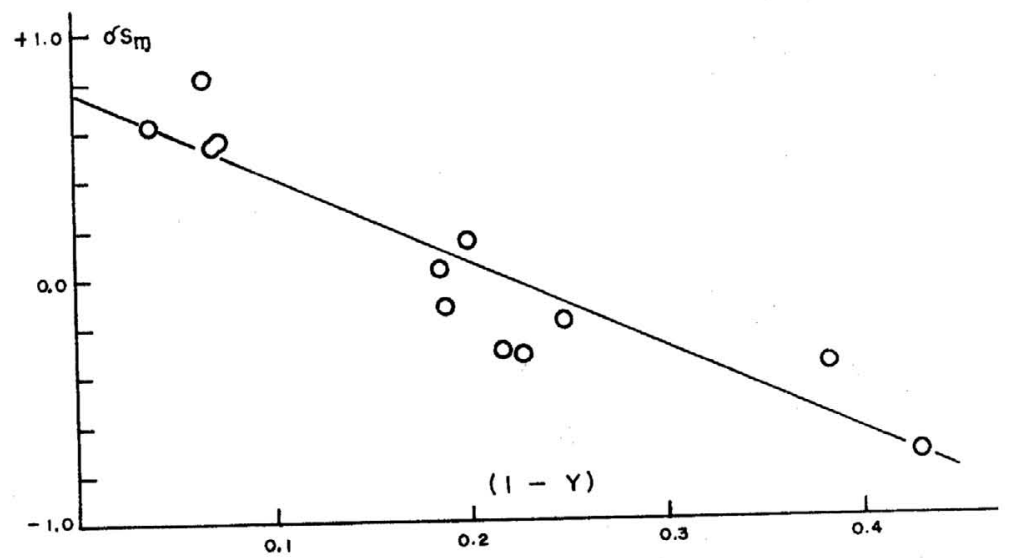

Fig. 2. Relation between the yield of sulfur dioxide and the isotope ratio at $1200^{\circ} \mathrm{C}$. The solid line is the least square fit for the observed points and is expressed in the equation: $\delta S_{m}=0.75-3.54(1-Y)$. 
ently wide range for comparison. In Fig. 2 are plotted against $(1-Y), \delta S_{m}$ of sulfur dioxide obtained at $1200^{\prime} \mathrm{C}$.

It is apparent that the observed isotope ratios $\left(\delta S_{m}\right)$ show a linear increase with the yield of sulfur dioxide as predicted by the equation 4). An estimated value for $\alpha$ from the Fig. 2 is $3.5 \times 10^{-3}$. Similarly, $\alpha$ at $1100^{\circ} \mathrm{C}$ is estimated to be $4.5 \times$ $10^{-3}$ from the less abundant data obtained at the temperature.

From the theoretical calculation by THODE et al. cited above, $\alpha$ should be ca. $2 \times 10^{-3}$ at $1200^{\circ} \mathrm{C}$. Agreement between the two types of estimation is rather excellent and it can be concluded that the isotope fractionation between sulfur dioxide and trioxide is really a main cause of error introduced during the combustion process at a high temperature. From our results, it is predicted that about $3 \%$ variation in the yield of sulfur dioxide at $1200^{\circ} \mathrm{C}$ would result in only $0.1 \%$ fluctuation in the isotope ratio measurement.

According to the theory of isotope exchange equilibrium, $\ln K_{i}$ is expected to vary with $1 / T^{2}$ at high temperatures, where $T$ is an absolute temperature (BIGELEISEN and MAyer, 1947). Thus, based on the value obtained at $1200^{\circ} \mathrm{C}, K_{i}$ or $\alpha$ at various temperatures can be estimated. It is then possible to calculate the corresponding value of $\delta S^{0}$ for each of the measured values, $\delta S_{m}$, at different conditions. The results of these calculations are summarized in Table 3 . It should be noted that the calculated values for $\delta S^{0}$ are close enough to each other to support the conclusion mentioned above. Furthermore, $6.5 \times 10^{-3}$ estimated for $\alpha$ at $800^{\circ} \mathrm{C}$ is comparable with $6.8 \times 10^{-3}$ observed by RAFTER (1957) as a fractionation factor between sulfate and sulfur dioxide at $700^{\circ} \mathrm{C}$.

Table 3. Fractionation factor $(\alpha)$ and estimated isotope ratio of $\mathrm{Ag}_{2} \mathrm{~S}$

\begin{tabular}{rcccc}
\hline \hline$T,{ }^{\circ} \mathrm{C}$ & $\alpha \times 10^{3}$ & Yield, \% & $\delta S_{m}, \%$ & $\delta S^{0}, \%$ \\
\hline 800 & 6.5 & 84.4 & -0.34 & +0.76 \\
900 & 5.5 & 88.6 & -0.08 & +0.54 \\
1000 & 4.6 & 84.8 & +0.43 & +1.14 \\
1100 & 4.0 & 82.0 & +0.07 & +0.78 \\
& & 92.8 & +0.54 & +0.85 \\
1200 & 3.5 & 57.1 & -0.74 & +0.75 \\
& & 61.7 & -0.37 & +0.96 \\
& & 78.3 & -0.31 & +0.45 \\
& & 80.0 & +0.15 & +0.85 \\
& & 93.1 & +0.81 & +0.96 \\
& & 96.2 & +0.61 & +0.74 \\
\hline
\end{tabular}

An improved technique for the combustion of silver sulfide After several tries to find out a better procedure to overcome the rapid decrease of the yield of sulfur dioxide, it is found that the use of a $\mathrm{N}_{2}-\mathrm{O}_{2}$ mixture in place of oxygen is the 
perfect solution to the problem. As is expected from the equation 2) and Table 2. it also gives a higher yield than the pure oxygen technique.

In a series of experiments carried out at $1200^{\circ} \mathrm{C}$, the yield was observed to increase steadily from 95 to $99 \%$ as $\mathrm{N}_{2} / \mathrm{O}_{2}$-ratio was raised stepwise from zero to 20 . Then, due to incomplete combustion of silver sulfide, the yield was suddenly decreased to $35 \%$. From these observations, the $\mathrm{N}_{2} / \mathrm{O}_{2}$-ratio of $15(\mathrm{v} / \mathrm{v})$ was selected to be the best for the routine isotope analysis.

The yield obtained by this procedure is ca. $98 \%$ at $1200^{\circ} \mathrm{C}$ and shows no sign of decrease even after more than 100 samples are treated in a same quartz tube. The devitrification of quartz, which takes place as it does in pure oxygen, does not seem to give any trouble in the mixed stream of nitrogen and oxygen.

Over a period of two years, a number of natural and synthetic sulfur compounds have been analyzed for the isotope ratios. Most of them are done in duplicate from the first step of chemistry and the deviations within each pair of runs are found to be less than $0.2 \%$ in most cases. Some of them are shown in Table 4 .

Samples No. 1 to 3 are obtained from the same standard barium sulfate which are analyzed repeatedly for the check of long-term reproducibility of our entire system.

Table 4. Reproducibility of the isotope ratio analysis in duplicate preparation

\begin{tabular}{|c|c|c|c|c|}
\hline No. & Sample & $\begin{array}{c}\text { Date of } \\
\text { Preparation } \\
\end{array}$ & Analysis & $\begin{array}{l}\delta S \\
\% \\
\%\end{array}$ \\
\hline 1 & $\mathrm{BaSO}_{4}$ reagent & $\begin{array}{l}3 / 20 / 65 \\
3 / 20 / 65\end{array}$ & $\begin{array}{l}3 / 23 / 65 \\
3 / 24 / 65\end{array}$ & $\begin{array}{l}-3.90 \\
-4.02\end{array}$ \\
\hline 2 & " & $\begin{array}{l}6 / 10 / 65 \\
6 / 16 / 65\end{array}$ & $\begin{array}{l}6 / 11 / 65 \\
6 / 18,65\end{array}$ & $\begin{array}{l}-3.38 \\
-3.56\end{array}$ \\
\hline 3 & $" \prime$ & $\begin{array}{l}12 / 23 / 65 \\
12 / 24 / 65\end{array}$ & $\begin{array}{l}1 / 10 / 66 \\
1 / 13 / 66\end{array}$ & $\begin{array}{l}-3.68 \\
-3.86\end{array}$ \\
\hline 4 & $\begin{array}{l}\mathrm{Ag}_{2} \mathrm{~S} \text { from reagent sodium } \\
\text { sulfide }\end{array}$ & $\begin{array}{l}3 / 9 / 65 \\
3 / 9 / 65\end{array}$ & $\begin{array}{l}3 / 19 / 65 \\
3 / 19 / 65\end{array}$ & $\begin{array}{l}+10.74 \\
+10.80\end{array}$ \\
\hline 5 & $\begin{array}{l}\text { Sedimentary pyrite in a } \\
\text { uranium deposit }\end{array}$ & $\begin{array}{l}1 / 26 / 66 \\
1 / 28 / 66\end{array}$ & $\begin{array}{l}1 / 31 / 66 \\
2 / 1 / 66\end{array}$ & $\begin{array}{l}-27.31 \\
-27.06\end{array}$ \\
\hline 6 & Pyrite, hydrothermal & $\begin{array}{l}1 / 26 / 66 \\
1 / 28 / 66\end{array}$ & $\begin{array}{l}1 / 31 / 66 \\
2 / 1 / 66\end{array}$ & $\begin{array}{l}+3.69 \\
+3.84\end{array}$ \\
\hline 7 & Pyrite in arkose sand & $\begin{array}{l}1 / 27 / 66 \\
3 / 28 / 66\end{array}$ & $\begin{array}{l}2 / 1 / 66 \\
4 / 5 / 66\end{array}$ & $\begin{array}{l}+18.18 \\
+17.95\end{array}$ \\
\hline 8 & Pyrite in metadiabase & $\begin{array}{l}12 / 24 / 65 \\
12 / 24 / 65\end{array}$ & $\begin{array}{l}1 / 12 / 66 \\
1 / 11 / 66\end{array}$ & $\begin{array}{l}-2.00 \\
-1.71\end{array}$ \\
\hline 9 & Pyrite in metadiabase & $\begin{array}{l}12 / 24 / 65 \\
12 / 24 / 65\end{array}$ & $\begin{array}{l}1 / 13 / 66 \\
1 / 13 / 66\end{array}$ & $\begin{array}{r}+2.34 \\
+2.69\end{array}$ \\
\hline 10 & Pyrite in slate & $\begin{array}{l}12 / 24 / 65 \\
12 / 24 / 65\end{array}$ & $\begin{array}{l}1 / 12 / 66 \\
1 / 13 / 66\end{array}$ & $\begin{array}{l}+2.58 \\
+2.62\end{array}$ \\
\hline
\end{tabular}


Although the sample preparation including the reduction of sulfate seems to be reproducible within $0.2 \%$ in each of these samples, there still remains a systematic error up to $0.5 \%$ which is probably due to the mass spectrometer system. This types of unpredicted error should be corrected by careful analysis of a stocked sulfur dioxide standard from time to time.

Recently, Ricke (1964) also presented a method to suppress the formation of sulfur trioxide to a considerable extent, where sulfide is oxidized to sulfur dioxide by vanadium pentoxide at $1000^{\circ} \mathrm{C}$ in an evacuated sealed quartz tube. An essential feature of this technique can also be ascribed to a low partial pressure of oxygen in the reaction vessel. The benefit of the $\mathrm{V}_{2} \mathrm{O}_{5}$-technique is undoutedly in the point that various types of sulfide can directly be converted into sulfur dioxide without their conversion to silver sulfide.

The $\mathrm{N}_{2}-\mathrm{O}_{2}$ combustion technique described in this paper, on the other hand, is simpler and less time consuming in the process of $\mathrm{SO}_{2}$-preparation The most of the chemical procedures required to obtain silver sulfide from various samples are inevitable when chemical analyses are wanted in parallel with the sulfur isotope analysis

\section{Acknowledgement}

The authors are greatly indebted to Dr. S. UMEMOTo of this Institute for his continuous encouragement and help throughout the establishment of the mass spectrometer system in this laboratory.

\section{REFERENCES}

Bigeleisen, J. and MAYER, G. M. (1957) Calculation of equilibrium constants of isotopic exchange reactions, J. Chem. Phys. 15, 261-7.

OANA, S. (1966) Sulfur isotopic fractionation between sulfur and sulfuric acid in the hydrothermal solution of sulfur dioxide, Geochem. J. 1, 45-50.

PITZER, K. S. and BREWER, L. (1961) Thermodynamics (Rivision of LEWS and RANDALL), McGraw-Hill, p. 685.

RAFTER, T. A. (1957) Sulphur isotopic variation in nature. Part I, The preparation of sulphur dioxide for mass spectrometre examination, N. Z. J. Sci. Tech. B, 38, 969; Part IIl, A study of the combustion characteristics of silver sulphide and lead sulphide for sulphur isotopic measurements. ibid. B, 38, 969-981.

RICKE, W. (1964) Präparation von Schwefeldioxid zur massen-spektrometrischen Bestimmung des Schwefel-Isotopen-Verhältnisses ${ }^{32} \mathrm{~S} /{ }^{31} \mathrm{~S}$ in natürichen Schwefelverbindungen. Z. anal. Chem. 199, 401-413.

SAKAI, H. (1966) Mass spectrometer systems for the isotope geochemistry II, Precision measurement of the isotope ratio of volatile elements. Mass Spectroscopy 14, 72-77.

Thode, H. G., MONSTER, J., and DUNFORD, R. B. (1961) Sulphur isotope geochemistry, Geochim. Cosmochim. Acta 25, 159-174.

WANLESS, R. K. and THODE, H. G. (1953) A mass spectrometer for high precision isotope ratio determinations. J. Sci. Instr. 30, 395-398. 


\section{Comment}

In the geochemical studies of stable isotopes more detailed examination of isotopic fractionation will be required to explain more precisely geochemical phenomena. From the investigation of isotopic exchange and unidirectional reaction, the temperature and the mechanism of reactions can be estimated. The estimation is made by measuring the isotpic fractionation between two forms of compounds and the result is required to be as accurate as possible. For instance, in the fraction ation between $\mathrm{SO}_{4}{ }^{-}$and $\mathrm{S}^{=}, 0.1 \%$ uncertainty in a $\delta \mathrm{S}$ value possibly introduces an error of 00001 in an equilibrium constant, corresponding to $2^{\circ} \mathrm{C}$ in a calculated temperature at about 1.030 of fractionation factor.

Recent advances in the technique of mass spectrometry have given us many isotopic results of sulfur which are accurate enough to get a reproducibility of \pm 0.1 to $\pm 0.15 \%$ in $\delta S$ value. However, it is known for long time that an error is introduced by the chemical conversion of sulfur samples to $\mathrm{SO}_{2}$ for mass spectrometric analysis. The final burning process of $\mathrm{Ag}_{2} \mathrm{~S}$ to $\mathrm{SO}_{2}$ usually shows only 90 to $95 \%$ yield. Sample preparation procedure should be developed to produce $\mathrm{SO}_{2}$ free from impurity and in good yield so as to avoid sulfur isotope fractionation.

The authors have made an important contribution to the problems of the burning procedure. This should be appreciated inasmuch as more accurate $o^{3+} \mathrm{S}$ values are promised in the field of geochemistry.

Department of Earth Sciences

Nagoya University

NobUyuki NakaI 